\title{
Dieulouard
}

Les Feuillettes

\section{Magali Mondy}

\section{(2) OpenEdition}

Journals

Édition électronique

URL : http://journals.openedition.org/adlfi/9139

ISSN : 2114-0502

Éditeur

Ministère de la culture

Référence électronique

Magali Mondy, "Dieulouard », ADLFI. Archéologie de la France - Informations [En ligne], Lorraine, mis en ligne le 01 mars 2001, consulté le 03 mai 2019. URL : http://journals.openedition.org/adlfi/9139

Ce document a été généré automatiquement le 3 mai 2019.

(c) Ministère de la Culture et de la Communication, CNRS 


\title{
Dieulouard
}

\author{
Les Feuillettes
}

\section{Magali Mondy}

Identifiant de l'opération archéologique : F1354200100011

Date de l'opération : 2001 (SU)

1 L'extraction de gravier, au lieu-dit "Les Feuillettes" par la société Orsa Granulats Lorraine, a été l'occasion de sondages dont un a révélé un fond de cabane de 2,90 m de côté. Un décapage, réalisé sur une surface d'environ $130 \mathrm{~m}^{2} \mathrm{n}$ 'a pas permis de mettre au jour d'autres structures qui auraient pu lui être associées. (Fig. $n^{\circ} 1$ : Relevés en plan et en coupe du fond de cabane, de la fosse (St. 2) et des poteaux 1 et 2)

2 Le fond de cabane, conservé sur 0,19 $\mathrm{m}$ de profondeur, était pourvu de deux poteaux aménagés en vis à vis sur deux côtés opposés; une petite fosse de forme oblongue occupait un quart de la structure.

3 La nature du comblement de l'ensemble de ces creusements est identique : composé d'un limon légèrement argileux de couleur brun foncé, il contenait un très important nombre de tessons de céramique, trois petits fragments de verre, un poids perforé d'environ $0,10 \mathrm{~m}$ de diamètre en calcaire oolithique, une dizaine de galets provenant de la Moselle et des os de porc et de bœuf.

4 La céramique est, pour l'essentiel, composée de fragments à pâte grossière et à dégraissant végétal. Un seul tesson provient d'un vase à dégraissant coquiller. La céramique fine à pâte claire est représentée par trois ensembles, dont l'un porte un décor estampé en dent de loup.

5 Mis à part les trois fragment de verre datés de l'époque mérovingienne, l'ensemble de la céramique mise au jour dans le comblement des structures serait davantage caractéristique de la période comprise entre les $\mathrm{IX}^{\mathrm{e}} \mathrm{s}$. et XII ${ }^{\mathrm{e}} \mathrm{s}$. dans la région.

MONDY Magali 


\section{ANNEXES}

Fig. $\mathrm{n}^{\circ} 1$ : Relevés en plan et en coupe du fond de cabane, de la fosse (St. 2) et des poteaux 1 et 2

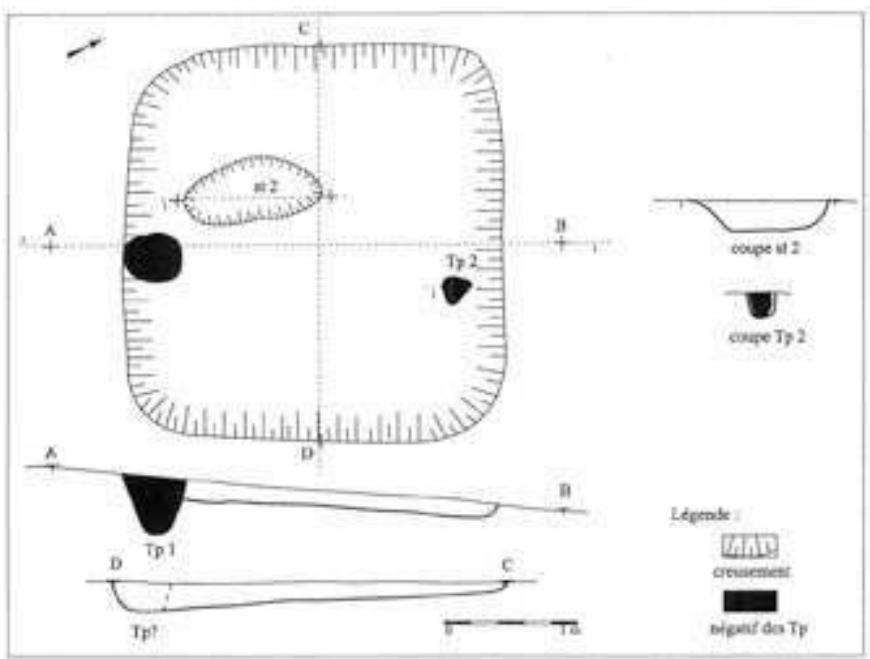

Auteur(s) : (INRAP). Crédits : INRAP (2001)

INDEX

Index géographique : Lorraine, Meurthe-et-Moselle (54), Dieulouard operation Sauvetage urgent (SU)

Index chronologique : haut Moyen Âge

Thèmes : bœuf, céramique médiévale, estampage, fond de cabane, fosse, ossement animal, poids, porc, verre

\section{AUTEUR}

MAGALI MONDY

AFAN 